OPEN ACCESS

Edited by:

Daniela Ceccarelli,

Research Executive Agency,

European Commission, Belgium

Reviewed by:

Maria M. Lleo,

University of Verona, Italy

Learn-Han Lee,

Monash University Malaysia, Malaysia

Biao Kan,

National Institute for Communicable

Disease Control and Prevention

(China CDC), China

*Correspondence:

Shuai Wang

handsomew@foxmail.com

Jianping Zhang

421325051@qq.com

Xueyang Zhang

jjy861120@163.com

†These authors have contributed equally to this work

Specialty section:

This article was submitted to Antimicrobials, Resistance

and Chemotherapy,

a section of the journal

Frontiers in Microbiology

Received: 25 March 2019

Accepted: 24 June 2019

Published: 18 July 2019

Citation:

He Y, Wang S, Zhang J, Zhang $X$,

Sun F, He B and Liu X (2019)

Integrative and Conjugative

Elements-Positive Vibrio parahaemolyticus Isolated From Aquaculture Shrimp in Jiangsu, China. Front. Microbiol. 10:1574. doi: 10.3389/fmicb.2019.01574

\section{Integrative and Conjugative Elements-Positive Vibrio parahaemolyticus Isolated From Aquaculture Shrimp in Jiangsu, China}

\author{
Yu He ${ }^{1,2+}$, Shuai Wang ${ }^{1,2 * t}$, Jianping Zhang ${ }^{1,2 *}$, Xueyang Zhang ${ }^{3 *}$, Fengjiao Sun ${ }^{4}$, Bin $\mathrm{He}^{5}$ \\ and Xiao Liú
}

\begin{abstract}
${ }^{1}$ College of Food Biological Engineering, Xuzhou University of Technology, Xuzhou, China, ${ }^{2}$ Key Construction Laboratory of Food Resources Development and the Quality Safety in Jiangsu, Xuzhou University of Technology, Xuzhou, China, ${ }^{3}$ College of Environmental Engineering, Xuzhou University of Technology, Xuzhou, China, ${ }^{4}$ Logistics \& Security Department, Shanghai Civil Aviation College, Shanghai, China, ${ }^{5}$ Environment Monitoring Station, Zaozhuang Municipal Bureau of Ecology and Environment, Zaozhuang, China, ${ }^{6}$ Henan Key Laboratory of Cold Chain Food Quality and Safety Control, Zhengzhou University of Light Industry, Zhengzhou, China
\end{abstract}

The development of multidrug- and toxin-resistant bacteria as a result of increasing industrialization and sustained and intense antimicrobial use in aquaculture results in human health problems through increased incidence of food-borne illnesses. Integrative and conjugative elements (ICEs) are self-transmissible mobile genetic elements that allow bacteria to acquire complex new traits through horizontal gene transfer and encode a wide variety of genetic information, including resistance to antibiotics and heavy metals; however, there is a lack of studies of ICEs of environmental origin in Asia. Here, we determined the prevalence, genotypes, heavy metal resistance and antimicrobial susceptibility of 997 presumptive strains of Vibrio parahaemolyticus $\left(t / h^{+}, t d h^{-}\right)$, a Gram-negative bacterium that causes gastrointestinal illness in humans, isolated from four species of aquaculture shrimp in Jiangsu, China. We found that 59 of the 997 isolates (5.9\%) were ICE-positive, and of these, 9 isolates tested positive for all resistance genes. BLAST analysis showed that similarity for the eight strains to V. parahaemolyticus was 99\%. Tracing the $V$. parahaemolyticus genotypes, showed no significant relevance of genotype among the antimicrobial resistance strains bearing the ICEs or not. Thus, in aquaculture, ICEs are not the major transmission mediators of resistance to antibiotics or heavy metals. We suggest future research to elucidate mechanisms that drive transmission of resistance determinants in $V$. parahaemolyticus.

Keywords: Vibrio parahaemolyticus, antimicrobial susceptibility, integrative and conjugative elements, heavy metal resistance, genotypes

\section{INTRODUCTION}

Microbes rapidly acquire or donate new genes and phenotypes through the process of horizontal gene transfer between organisms that is a key driver of microbial evolution (Pan et al., 2019). Integrative and conjugative elements (ICEs) are self-transmissible modular mobile genetic elements (MGEs) integrated into a host genome that are passively propagated during chromosomal 
replication and cell division, and mediate the acquisition of complex new traits in bacteria (Johnson and Grossman, 2015). Recent studies have shown these MGEs contain cargo genes encoding traits including resistance, virulence, novel carbon source metabolism, and degradation of aromatic compounds, that may benefit the recipient bacteria (Rubio-Cosials et al., 2018; $\mathrm{Xu}$ et al., 2018). ICEs tend to be mosaic and modular, ranging from 20 to $>500 \mathrm{~kb}$. ICEs are excised from the host chromosome and then transfer to recipients via conserved conjugation machinery in the type IV secretion system (Flores-Ríos et al., 2019), prior to reintegration into the host chromosome.

Vibrio parahaemolyticus is a Gram-negative, halophilic, mesophilic, aerobic bacterium common in warm climate marine and estuarine environments. Pathogenic strains in food cause serious health issues to humans, including gastroenteritis, septicemia, and wound infection (He et al., 2016). Shrimp represents an important reservoir of $V$. parahaemolyticus, particularly in fresh and refrigerated stock, but it is also recorded from frozen stock. China is the world's largest producer of aquatic products ( $\mathrm{He}$ et al., 2016). However, industrial development and use of antimicrobials in aquaculture have led to increased heavy metal pollution and development of multidrug resistant (MDR) bacteria that are problematic in many aquatic systems as they drive incidence of foodborne illnesses (Lopatek et al., 2018). Previous studies have revealed that bacteria can acquire resistance via conjugation or transformation to induce a wide variety of disease and adapt to the harsh environment (Matyar, 2012). The World Health Organization (WHO) produced a global map of antimicrobial resistance, warning that a "post-antibiotic" world could soon become a reality in April 2014 (WHO, 2014). Recent studies indicated that drugs which were once lifesavers are now worthless, for instance, chloramphenicol, once a physician's first choice against typhoid, is no longer effective in many parts of the world and resistance has spread around the world (Woolhouse and Farrar, 2014). Antimicrobial resistance is a global problem that requires global solutions, better surveillance is essential. Nevertheless, to date, no global approaches were conducted on further demonstrating the characterization of the $V$. parahaemolyticus isolates present in shrimp-production industry, despite their great significance in economy and human health.

The discovery and early studies of ICEs were stimulated by interest in bacterial resistance to antibiotics and heavy metals, and how that resistance was spread. MGEs with ICE-like properties have been described in several species of Gammaproteobacteria, particularly Vibrio (Liu et al., 2019). However, few studies report on ICEs in $V$. parahaemolyticus isolates from Asia. Hence, in this study, we focused on analyzing the $V$. parahaemolyticus strains from different shrimp samples in Jiangsu, China to determine the antibiotic and heavy metal resistance of these bacteria and to investigate the relationship between antibiotic and heavy metal. Molecular characterization and phenotypes of antibiotic resistance and heavy metals have been characterized. The information will facilitate the better understanding of this bacterium and facilitate related risk assessment and health management for consuming seafood.

\section{MATERIALS AND METHODS}

\section{Sample Collection}

Freshwater shrimp (Procambarus clarkii, Macrobrachium nipponense, Penaeus vannamei, and Macrobrachium rosenbergii), which are commonly shrimp breeds in China were collected once a month from Xuzhou Kaiming Fish Market, Jiangsu, China from May to October 2016-2018. P. clarkii and M. nipponense are key economic species in Jiangsu; $P$. vannamei and $M$. rosenbergii are cultured widely in the littoral provinces of southeastern China. We randomly collected samples of each species following a modified version of a standard protocol (Kaysner and DePaola, 2004). Samples were placed in sterile plastic bags (Shanghai Sangon Biological Engineering Technology and Services Co., Ltd., Shanghai, China) and taken to the laboratory on ice for homogenization within $2 \mathrm{~h}$ of collection.

\section{V. parahaemolyticus Isolation and Identification}

Vibrio parahaemolyticus was isolated and identified as described by the Chinese Government Standard (GB17378-2007) and He et al. (2016). Shrimp (25 g) were rinsed with sterile saline solution then homogenized for $60 \mathrm{~s}$ in sterile bags (Stomacher) containing $225 \mathrm{~mL}$ of sterile saline. Serial 10 fold dilutions (to $1: 10^{4}$ ) were prepared, and $100 \mu \mathrm{l}$ of each dilution were spread on thiosulfate citrate-bile salts-sucrose plates (TCBS; Beijing Land Bridge Technology Company Ltd., Beijing, China) which were incubated for $16 \mathrm{~h}$ at $37^{\circ} \mathrm{C}$. Putative $V$. parahaemolyticus colonies (which are green on TCBS) were placed separately in wells of 96-well microtiter plates containing $200 \mu \mathrm{l}$ of sterile alkaline peptone water plus $3 \%$ $\mathrm{NaCl}(\mathrm{pH} 8.5 \pm 0.2)$.

\section{Screening and Identification of Virulence and ICE Genes}

Presumptive $V$. parahaemolyticus colonies $(N=25$ per species of shrimp) were selected, screened, and identified using PCRbased screening of the species-specific marker gene thermolabile hemolysin (tlh). Table $\mathbf{1}$ lists primers used in this study. In th-positive $V$. parahaemolyticus strains, the virulenceassociated genes thermostable direct hemolysin $(t d h)$ and TDH-related hemolysin (trh), SXT/R391-like ICE conserved genes (int, attR, traC, setR, and traI), and the typical resistance genes for streptomycin $(\operatorname{str} A / s \operatorname{tr} B)$, trimethoprim (dfrA1/dfr18), and sulfamethoxazole/trimethoprim (sul2) were identified using primers as described by $\mathrm{He}$ et al. (2015a, 2016) and Beker et al. (2018). Strain taxonomy was determined from 16S rRNA gene sequences, obtained using primer pair 27F and 1492R; sequencing was performed by Shanghai Sangon Biological Engineering Technology and Services Co., Ltd., (Shanghai, China) (He et al., 2016). V. parahaemolyticus ATCC33846 $\left(t d h^{+}, t r h^{-}\right)$and ATCC17802 $\left(t d h^{-}, t r h^{+}\right)$were used as positive controls. Genomic DNA was prepared using a MiniBest bacterial genomic DNA extraction kit (v. 2.0; Japan TaKaRa BIO, Dalian, China). DNA was amplified using a 
Mastercycler pro PCR thermal cycler (Eppendorf, Hamburg, Germany). DNA sequences were assembled into contigs using ContigExpress software ${ }^{1}$. Protein functions were analyzed using BLAST ${ }^{2}$.

\section{Susceptibility to Antimicrobials and Heavy Metals}

In vitro susceptibility of isolates to antimicrobial agents according to the guidance of the Performance Standards

${ }^{1}$ http://www.contigexpress.com

${ }^{2}$ http://ncbi.nlm.nih.gov/BLAST

TABLE 1 | Primers used in this study.

\begin{tabular}{|c|c|c|c|}
\hline Primer & Nucleotide sequence $\left(5^{\prime}-3^{\prime}\right)$ & Target genes & References \\
\hline $27 \mathrm{~F}$ & AGAGTTTG ATCCTGGCTCAG & $16 S$ rDNA & $\begin{array}{l}\text { Weisburg et al., } \\
1991\end{array}$ \\
\hline $1492 R$ & GGTTACC TITACGACTTG & & \\
\hline L-TLH & $\begin{array}{l}\text { AAAGCGGAT } \\
\text { TATGCAGAAGCACTG }\end{array}$ & th & $\begin{array}{l}\text { Panicker et al., } \\
2004\end{array}$ \\
\hline R-TLH & АCTITCTAGC ATITCTCTGC & & \\
\hline Tdh-1 & $\begin{array}{l}\text { CCATCTGTCC } \\
\text { CПITCCTGCC }\end{array}$ & $t d h$ & $\begin{array}{l}\text { Panicker et al., } \\
2004\end{array}$ \\
\hline tdh- $4 c$ & ССАСТАССА СТСТСАТАТGС & & \\
\hline VPTRH-L & $\begin{array}{l}\text { TTGGCTTCG } \\
\text { ATATTITCAGTATCT }\end{array}$ & trh & $\begin{array}{l}\text { Panicker et al., } \\
2004\end{array}$ \\
\hline VPTRH-R & $\begin{array}{l}\text { CATAACAAAC } \\
\text { ATATGCCCATTTCCG }\end{array}$ & & \\
\hline \multirow[t]{2}{*}{ tral- $F$ tral- $R$} & GCAAGT CCTGATCCGCTATC & tral & Bani et al., 2007 \\
\hline & CCAGGGCAT CTCATATGCGT & & \\
\hline traC-F & $\begin{array}{l}\text { TTGACGCT } \\
\text { GTTTCACCAACG }\end{array}$ & traC & Bani et al., 2007 \\
\hline traC-R & GGCACGAC CTIIITCTCCC & & \\
\hline setR-F & ACGGCGGA GATGTIITGT & setR & Bani et al., 2007 \\
\hline setR-R & GTGCGCC AATGCTCAGTT & & \\
\hline attR-F & GGTTAG CCACAGTTGTTC & attR & Song et al., 2013 \\
\hline attR-R & CGTCAG GGTGCGAGAT & & \\
\hline Int-F & GACGCATT TCATCCAGG & int & Song et al., 2013 \\
\hline Int-R & GCAACAG CGGGTAGACA & & \\
\hline SUL2-F & AGGGGGC AGATGTGATCGC & sul2 & Falbo et al., 1999 \\
\hline SUL2-B & $\begin{array}{l}\text { TGTGCGG } \\
\text { ATGAAGTCAGCTCC }\end{array}$ & & \\
\hline STRA-F & $\begin{array}{l}\text { TTGATGT } \\
\text { GGTGTCCCGCAATGC }\end{array}$ & strA & $\begin{array}{l}\text { Dalsgaard et al., } \\
1999\end{array}$ \\
\hline STRA-B & $\begin{array}{l}\text { CCAATCG } \\
\text { CAGATAGAAGGCAA }\end{array}$ & & \\
\hline strB-F & GGCACCC ATAAGCGTACGCC & strB & $\begin{array}{l}\text { Dalsgaard et al., } \\
1999\end{array}$ \\
\hline strB-R & $\begin{array}{l}\text { TGCCGAG } \\
\text { CACGGCGACTACC }\end{array}$ & & \\
\hline dfr1-F & CGAAGAA TGGAGTTATCGGG & dfra1 & $\begin{array}{l}\text { Iwanaga et al., } \\
2004\end{array}$ \\
\hline dfr1-B & TGCTGG GGATTTCAGGAAAG & & \\
\hline TMP-F & $\begin{array}{l}\text { TGGGTAA } \\
\text { GACACTCGTCATGGG }\end{array}$ & dfr18 & Falbo et al., 1999 \\
\hline TMP-B & $\begin{array}{l}\text { ACTGCCG } \\
\text { TाTCGATAATGTGG }\end{array}$ & & \\
\hline
\end{tabular}

for Antimicrobial Disk Susceptibility Tests of the Clinical and Laboratory Standards Institute (CLSI) (2006, Approved Standard-Ninth Edition, M2-A9, Vol. 26 No. 1) following the approach described by Song et al. (2013) and He et al. (2015a). Mueller-Hinton agar medium (Oxoid, United Kingdom), and the discs (Oxoid, United Kingdom) were used in this study. Examined antimicrobial agents included: $30 \mu \mathrm{g}$ of chloramphenicol (CHL); $10 \mu \mathrm{g}$ of gentamicin (CN); $25 \mu \mathrm{g}$ of sulfamethoxazole/trimethoprim 19:1 (SXT); $5 \mu \mathrm{g}$ of rifampin (RIF); $30 \mu \mathrm{g}$ of tetracycline (TET); $10 \mu \mathrm{g}$ of ampicillin (AMP); $100 \mu \mathrm{g}$ of spectinomycin (SPT); $30 \mu \mathrm{g}$ of kanamycin (KAN); $5 \mu \mathrm{g}$ of trimethoprim (TM); and $10 \mu \mathrm{g}$ of streptomycin (STR). The assays were performed in triplicate experiments, and reference strain Escherichia coli ATCC25922 was purchased from the Institute of Industrial Microbiology (Shanghai, China) and used for quality control. Broth Dilution Testing (microdilution) was used to measure quantitatively the minimal inhibitory concentration (MIC) in vitro of the tested heavy metals against the strains, according to the Methods for Dilution Antimicrobial Susceptibility Tests for Bacteria That Grow Aerobically (2006, CLSI, Approved Standard-Seventh Edition, M7-A7, Vol. 26 No. 2). The heavy metals tested were: $\mathrm{NiCl}_{2}, \mathrm{CrCl}_{3}, \mathrm{CdCl}_{2}, \mathrm{PbCl}_{2}, \mathrm{CuCl}_{2}$, $\mathrm{ZnCl}_{2}, \mathrm{BaCl}_{2}$, and $\mathrm{HgCl}_{2}$ (Sinopharm Chemical Reagent Co., Ltd., Shanghai, China); E. coli K12 MG1655 strain was used as the control.

\section{Molecular Typing of V. parahaemolyticus Strains}

Vibrio parahaemolyticus was cultured in Luria-Bertani broth (Beijing Land Bridge Technology Co.) following methods described by $\mathrm{He}$ et al. (2015b). Genomic DNA was extracted using a CHEF Bacterial DNA Plug Kit (Bio-Rad Laboratories, Hercules, CA, United States). Agarose plugs were prepared by mixing equal volumes of cell suspension, and each plug was digested using Not (Japan TaKaRa BIO). Electrophoresis was performed at $6 \mathrm{~V} / \mathrm{cm}, 14^{\circ} \mathrm{C}$, at a field angle of $120^{\circ}$, using 1\% SeaKem Gold agarose (Lonza, Basel, Switzerland). Pulsed-field gel electrophoresis (PFGE) patterns were visualized under 260-nm light; images were recorded using the UVP EC3 Imaging system (UVP LLC), and data were analyzed using NTSYSpc 2.10e software.

\section{RESULTS AND DISCUSSION}

\section{V. parahaemolyticus Isolation and Identification}

Procambarus clarkii, M. nipponense, $P$. vannamei, and $M$. rosenbergii are common species of shrimp consumed in Jiangsu, China, and PCR analysis showed that 997 of 1800 (55.4\%) bacterial isolates obtained from them tested positive for the $V$. parahaemolyticus-specific th gene. There were distinct temporal patterns of $t$ lh-positive prevalence (Figure 1); over the 3 -year study, th gene abundance was greater during the summer months (July and August) when temperature is highest. 


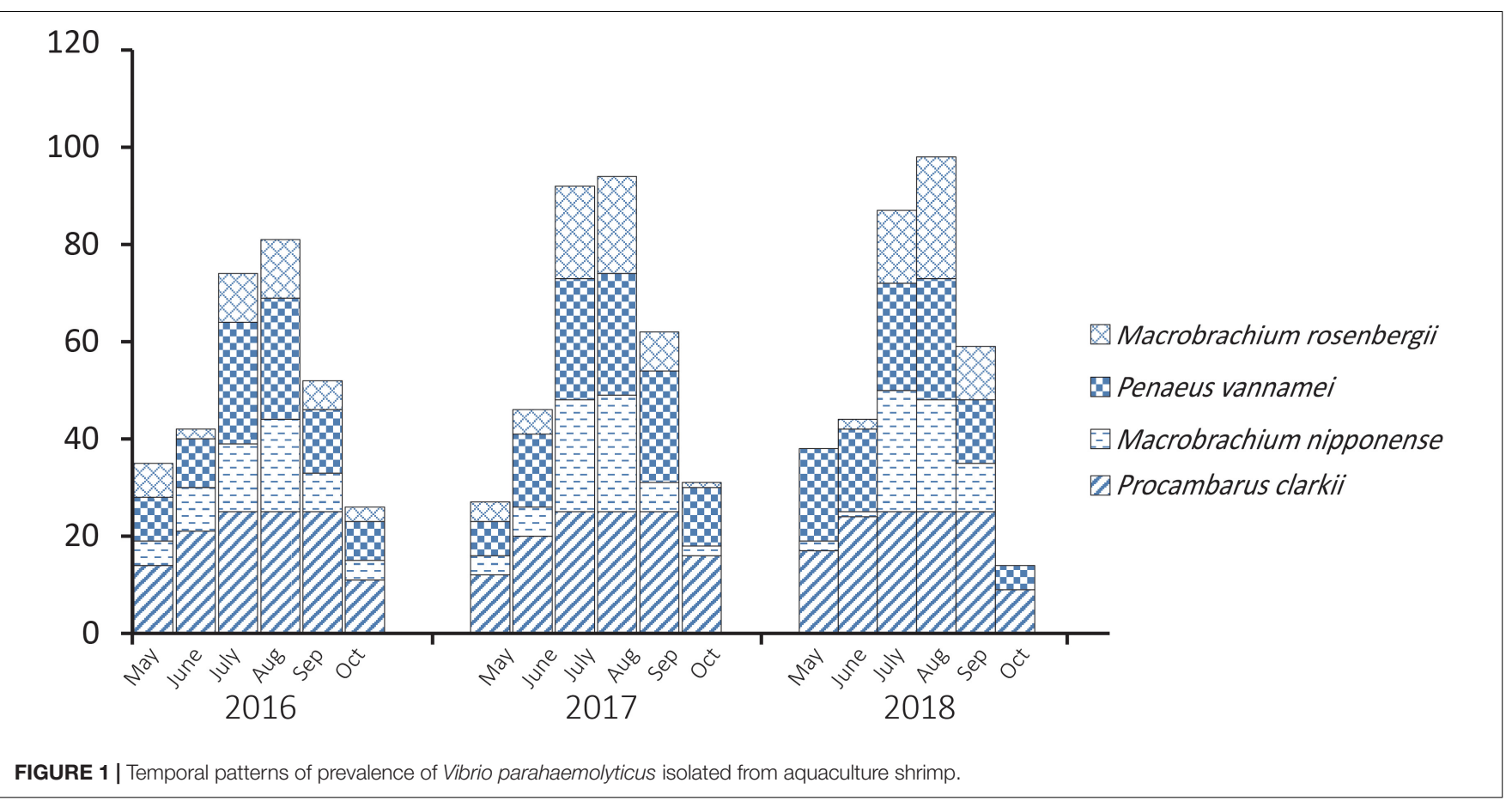

\section{Prevalence of Virulence Associated-Genes and Conserved ICE Genes}

Pathogenic $V$. parahaemolyticus produces two major toxic proteins, $\mathrm{TDH}$ and $\mathrm{TRH}$, that are important in the diarrheal diseases caused by this species (Boyd et al., 2008). We tested the 997 th-positive strains for the presence of virulence-associated toxin genes $t d h$ and $t r h$, and found that most isolates were considered not virulent; we did not amplify $t d h$ from any isolate, and amplified trh from only two isolates (obtained from P. clarkii in August 2018). Similar very low incidence of pathogenic $V$. parahaemolyticus has been reported in many nonclinical samples (He et al., 2016; Hu and Chen, 2016; MartinezUrtaza et al., 2016; Lopatek et al., 2018; Zhao et al., 2018; Jiang et al., 2019).

Analysis of the highly conserved core genes of SXT/R391-like ICEs revealed that $59(5.9 \%)$ of the isolates tested positive for all five genes (int, attR, traC, setR, and traI). Occurrence was highest in isolates recovered from $P$. clarkii (33.9\%), followed by P. vannamei (32.2\%), M. nipponense (20.3\%), and M. rosenbergii (13.6\%), and resistance genes strA/strB, dfrA1/dfr 18 , and sul2 were recorded in $25.4,15.3$, and $33.9 \%$ of the 59 isolates, respectively, with nine strains testing positive for all three resistance genes (Table 2).

\section{Antimicrobial Susceptibility and Heavy Metal Tolerance}

Our results revealed distinct antibiotic-resistance patterns for the 59 isolates that were positive for the highly conserved ICE genes. All isolates were AMP resistant, and resistance to STR, TM, RIF, and SXT was 25.4, 22.0, 18.6, and 16.9\%, respectively; resistance to CHL, SPT, and KAN was $15.3 \%$ (Figure 2). We found that approximately $84.7,81.3,74.6$, and $72.9 \%$ of the isolates exhibited intermediate susceptibility to SPT, KAN, STR, and TM, and while $15.3 \%$ of isolates showed intermediate patterns of susceptibility to CN and TET, none of the isolates was resistant to these two antibiotics. We found nine isolates tested positive for the three resistance genes $\operatorname{str} A / \operatorname{str} B, d f r A 1 / d f r 18$, sul2, and these strains were resistant to CHL, SXT, RIF, AMP, SPT, KAN, TM, and STR, with intermediate susceptibility to CN and TET. BLAST analysis showed that the 16S rRNA gene sequence of isolate VpJHY15 shared 99\% similarity with that from Proteus vulgaris $^{3}$, and similarity for the other eight strains (VpJHY4, VpJHY9, VpJHY16, VpJHY35, VpJHY36, VpJHY39, VpJHY41, and VpJHY48) to $V$. parahaemolyticus was $99 \%$.

Therefore, in this study, eight $V$. parahaemolyticus isolates tested positive for SXT/R391-like ICE conserved genes (int, attR, traC, set $R, \operatorname{traI})$ and associated typical resistance genes (strA/strB, $d f r A 1 / d f r 18$, sul2). These strains may be described as having MDR phenotypes because they were resistant to at least one agent in $\geq 3$ categories of antimicrobial (Thapa Shrestha et al., 2015). These isolates were also examined for susceptibility to heavy metals (Malik and Aleem, 2011), we found minimal inhibitory concentrations (MICs) of $3200 \mu \mathrm{g} / \mathrm{mL}$ for $\mathrm{Ni}^{2+}, \mathrm{Cr}^{3+}, \mathrm{Cd}^{2+}$, $\mathrm{Cu}^{2+}, \mathrm{Pb}^{2+}$, and $\mathrm{Mn}^{2+} ; 1600 \mu \mathrm{g} / \mathrm{ml}$ for $\mathrm{Zn}^{2+}$; and $50 \mu \mathrm{g} / \mathrm{ml}$ for $\mathrm{Hg}^{2+}$ (Table 3). All strains were resistant to $\mathrm{Zn}^{2+}$ and $\mathrm{Pb}^{2+}$, and most also displayed tolerance to $\mathrm{Cu}^{2+}$ (87.5\%), $\mathrm{Cd}^{2+}$ (75\%), and $\mathrm{Hg}^{2+}(62.5 \%)$, while a few were resistant to $\mathrm{Cr}^{3+}$ (37.5\%), $\mathrm{Ni}^{2+}(25 \%)$, and $\mathrm{Mn}^{2+}(12.5 \%)$. V. parahaemolyticus isolates derived from the four shrimp species showed tolerance to at least four heavy-metal agents (Table 4). While we found

${ }^{3}$ http://rdp.cme.msu.edu/ 
TABLE 2 | Genotypes of $V$. parahaemolyticus isolated from shrimp.

\begin{tabular}{|c|c|c|c|c|c|c|c|c|c|c|c|c|c|}
\hline \multirow[t]{2}{*}{ Source (species) } & \multirow[t]{2}{*}{ Strain no. } & \multirow[t]{2}{*}{ Sample date } & \multirow[t]{2}{*}{$t / h$} & \multicolumn{2}{|c|}{ Virulence-associated genes } & \multicolumn{5}{|c|}{ ICEs conserved-core genes } & \multicolumn{3}{|c|}{ Resistance genes } \\
\hline & & & & $t d h$ & trh & int & attR & tral & $\operatorname{trac}$ & setR & strA/strB & dfrA1/dfr18 & sul2 \\
\hline \multirow[t]{20}{*}{ Procambarus clarkii } & VpJHY1 & July 2016 & + & - & - & + & + & + & + & + & - & - & + \\
\hline & VpJHY2 & July 2016 & + & - & - & + & + & + & + & + & - & - & - \\
\hline & VpJHY3 & August 2016 & + & - & - & + & + & + & + & + & + & - & + \\
\hline & VpJHY4 & August 2016 & + & - & - & + & + & + & + & + & + & + & + \\
\hline & VpJHY5 & August 2016 & + & - & - & + & + & + & + & + & - & - & - \\
\hline & VpJHYG & July 2017 & + & - & - & + & + & + & + & + & - & - & - \\
\hline & VpJHY7 & August 2017 & + & - & + & + & + & + & + & + & + & - & + \\
\hline & VpJHY8 & August 2017 & + & - & - & + & + & + & + & + & + & - & + \\
\hline & VpJHYg & August 2017 & + & - & - & + & + & + & + & + & + & + & + \\
\hline & VpJHY10 & August 2017 & + & - & - & + & + & + & + & + & - & - & - \\
\hline & VpJHY11 & September 2017 & + & - & - & + & + & + & + & + & - & - & - \\
\hline & VpJHY12 & September 2017 & + & - & - & + & + & + & + & + & - & - & - \\
\hline & VpJHY13 & July 2018 & + & - & - & + & + & + & + & + & - & - & - \\
\hline & VpJHY14 & July 2018 & + & - & - & + & + & + & + & + & - & - & - \\
\hline & VpJHY15 & August 2018 & + & - & + & + & + & + & + & + & + & + & + \\
\hline & VpJHY16 & August 2018 & + & - & - & + & + & + & + & + & + & + & + \\
\hline & VpJHY17 & August 2018 & + & - & - & + & + & + & + & + & - & - & - \\
\hline & VpJHY18 & September 2018 & + & - & - & + & + & + & + & + & + & - & + \\
\hline & VpJHY19 & September 2018 & + & - & - & + & + & + & + & + & - & - & - \\
\hline & VpJHY20 & September 2018 & + & - & - & + & + & + & + & + & - & - & - \\
\hline \multirow[t]{12}{*}{ Macrobrachium nipponense } & VpJHY21 & July 2016 & + & - & - & + & + & + & + & + & - & - & - \\
\hline & VpJHY22 & August 2016 & + & - & - & + & + & + & + & + & - & - & - \\
\hline & VpJHY23 & August 2016 & + & - & - & + & + & + & + & + & - & - & - \\
\hline & VpJHY24 & August 2017 & + & - & - & + & + & + & + & + & - & - & - \\
\hline & VpJHY25 & September 2017 & + & - & - & + & + & + & + & + & - & - & - \\
\hline & VpJHY26 & August 2018 & + & - & - & + & + & + & + & + & - & - & + \\
\hline & VpJHY27 & August 2018 & + & - & - & + & + & + & + & + & - & - & - \\
\hline & VpJHY28 & August 2018 & + & - & - & + & + & + & + & + & - & - & - \\
\hline & VpJHY29 & August 2018 & + & - & - & + & + & + & + & + & - & - & - \\
\hline & VpJHY30 & August 2018 & + & - & - & + & + & + & + & + & + & - & + \\
\hline & VpJHY31 & September 2018 & + & - & - & + & + & + & + & + & - & - & - \\
\hline & VpJHY32 & September 2018 & + & - & - & + & + & + & + & + & - & - & - \\
\hline \multirow[t]{3}{*}{ Penaeus vannamei } & VpJHY33 & July 2016 & + & - & - & + & + & + & + & + & - & - & - \\
\hline & VpJHY34 & August 2016 & + & - & - & + & + & + & + & + & - & - & - \\
\hline & VpJHY35 & August 2016 & + & - & - & + & + & + & + & + & + & + & + \\
\hline
\end{tabular}




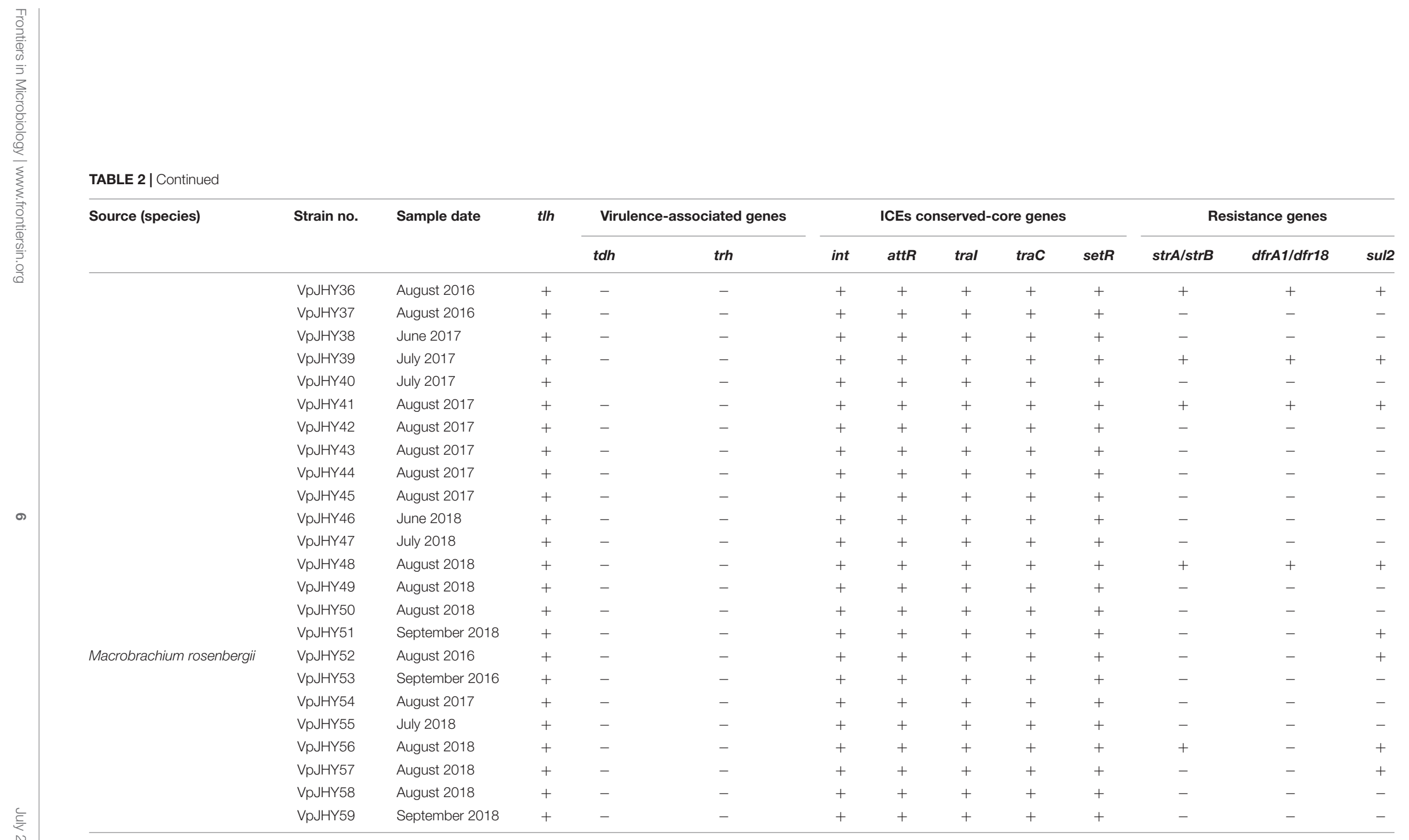




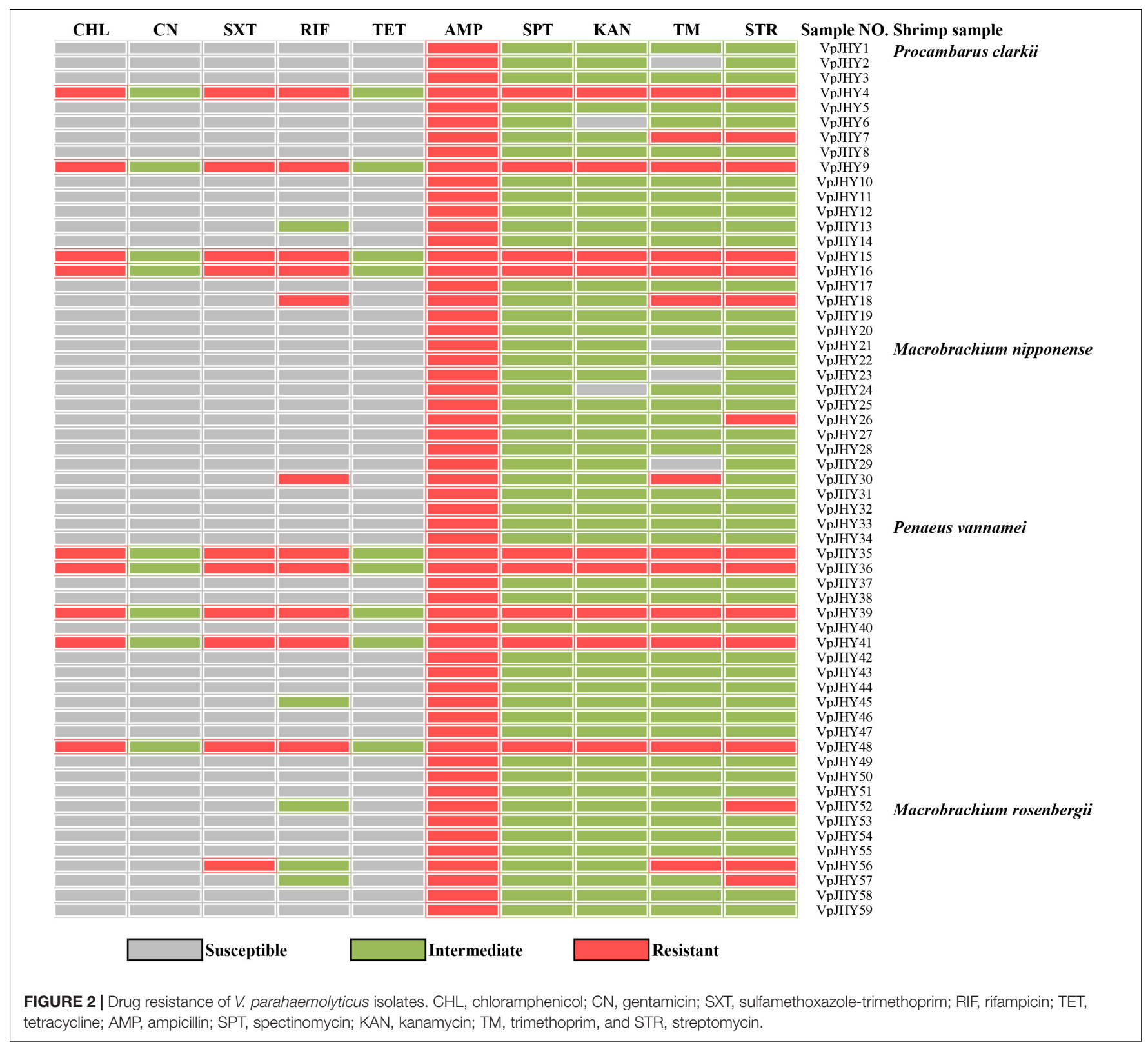

that resistance to heavy metals in $V$. parahaemolyticus did not vary with shrimp species, tolerance was shown to be very prevalent in ICE-positive strains with more than eight antibiotic resistance phenotypes. These contrasting results may be a result of inappropriate, variable releases of industrial wastes to aquaculture environments (Jiang et al., 2019), because industrial pollutants enhance selection for antibiotic resistance and vice versa. Abundant double-resistant bacteria threaten human health if contaminated products are consumed (Silva et al., 2018).

\section{Phylogenetic Relationships of Resistant V. parahaemolyticus Isolates}

Genomic DNA of the eight $V$. parahaemolyticus strains was individually digested with the restriction endonuclease NotI, and the resulting DNA fragments were resolved by PFGE. This analysis revealed different genomic finger prints of the strains tested (Figure 3). Fingerprinting analysis of the relatedness of the eight ICE-positive isolates produced 14 to 19 restriction bands that ranged from 20.5 to $1135 \mathrm{~kb}$. Cluster analysis of the PFGE profiles revealed seven pulsotypes with $\geq 87 \%$ similarity, which indicates isolates belonging to the same epidemic strain (Seifert et al., 2005). The isolates were assigned to four distinct clusters, with $62.5 \%$ assigned to Clusters A to $\mathrm{C}$ and one that was more distantly related assigned to Cluster D. Simpson's diversity index (0.9872) indicated high diversity among these isolates. Clustering analysis of the genomic fingerprints revealed eight distinguishable NotI-PFGE types, demonstrating that the MDR of ICEs-positive strains isolated for the prevalence analysis exhibited various genotypes. According 
TABLE 3 | Heavy metal resistance of $V$. parahaemolyticus isolates.

\begin{tabular}{|c|c|c|c|c|c|c|c|c|c|c|c|c|}
\hline \multirow[t]{2}{*}{ Heavy metals } & \multicolumn{10}{|c|}{ MIC $(\mu \mathrm{g} / \mathrm{mL})$} & \multicolumn{2}{|c|}{ Resistant } \\
\hline & 6.25 & 12.5 & 25 & 50 & 100 & 200 & 400 & 800 & 1600 & 3200 & $n$ & (\%) \\
\hline \multirow[t]{2}{*}{$\mathrm{Ni}$} & & & & & & & & a & & & & \\
\hline & & & & & & & 1 & 5 & 1 & 1 & 2 & 25 \\
\hline \multirow[t]{2}{*}{$\mathrm{Cr}$} & & & & & & & & $a$ & & & & \\
\hline & & & & & & & & 5 & 1 & 2 & 3 & 37.5 \\
\hline \multirow[t]{2}{*}{$\mathrm{Cd}$} & & & & & & & a & & & & & \\
\hline & & & & & & 1 & 1 & 4 & 2 & & 6 & 75 \\
\hline \multirow[t]{2}{*}{$\mathrm{Cu}$} & & & & & & & & $a$ & & & & \\
\hline & & & & & & & & 1 & 2 & 5 & 7 & 87.5 \\
\hline \multirow[t]{2}{*}{$\mathrm{Pb}$} & & & & & & & & & $\mathrm{a}$ & & & \\
\hline & & & & & & & & & & 8 & 8 & 100 \\
\hline \multirow[t]{2}{*}{$\mathrm{Mn}$} & & & & & & & & & $\mathrm{a}$ & & & \\
\hline & & & & & & & & & 7 & 1 & 1 & 12.5 \\
\hline \multirow[t]{2}{*}{$\mathrm{Zn}$} & & & & & & & $\mathrm{a}$ & & & & & \\
\hline & & & & & & & & 7 & 1 & & 8 & 100 \\
\hline \multirow[t]{2}{*}{$\mathrm{Hg}$} & & a & & & & & & & & & & \\
\hline & 2 & 1 & 3 & 2 & & & & & & & 5 & 62.5 \\
\hline
\end{tabular}

MIC, minimum inhibitory concentrations. ${ }^{a}$ Minimal inhibition concentration of standard strain E. coli K12.

TABLE 4 | Susceptibility of $V$. parahaemolyticus harboring the SXT/R391 family of integrative and conjugative elements to heavy metals and antibiotics.

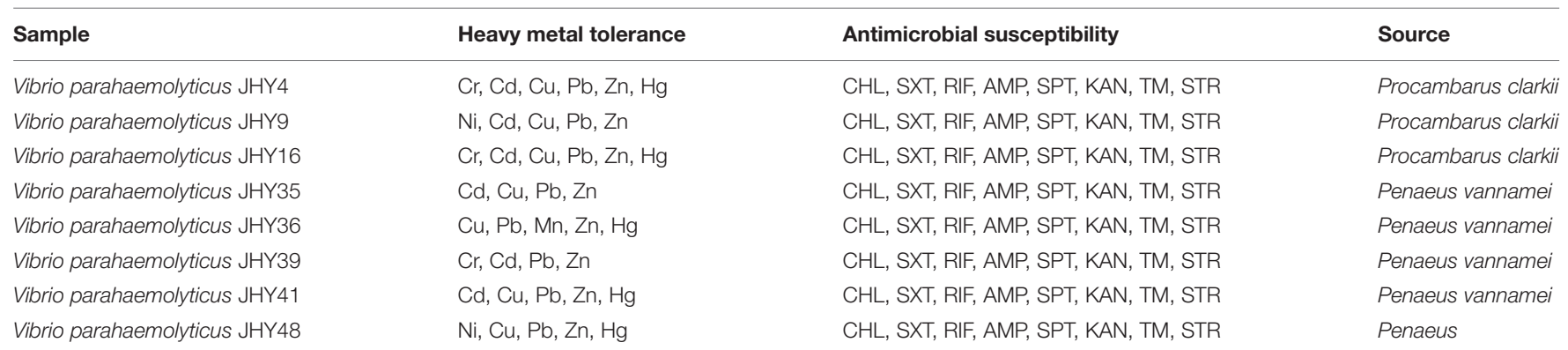

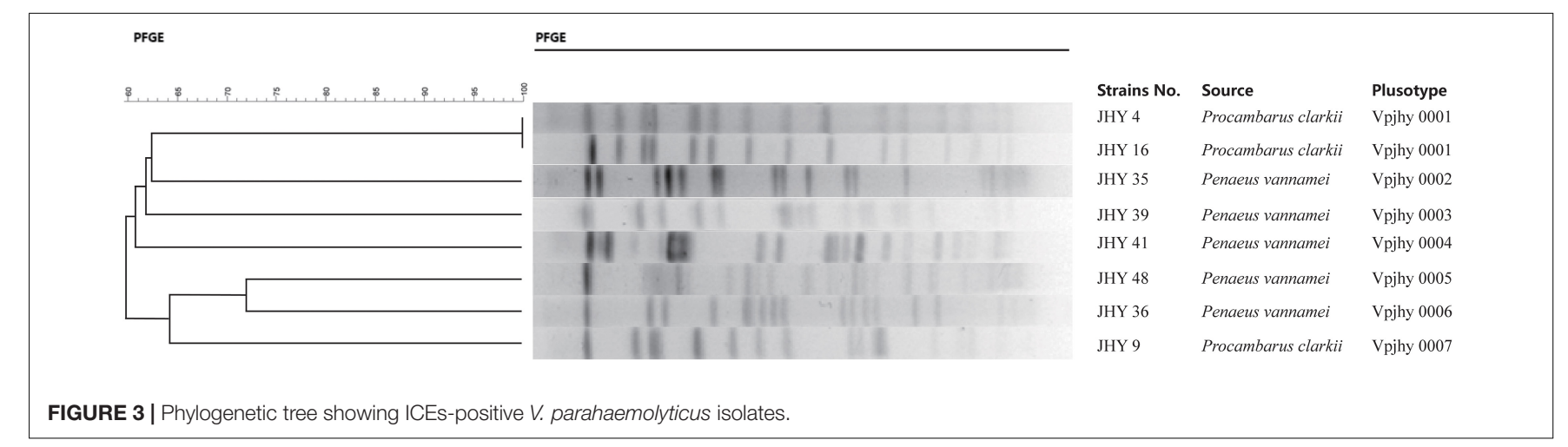

to our previous studies, the presence or absence of ICEs has no significant relevance among these strains in terms of antimicrobial resistance ( $\mathrm{He}$ et al., 2015a), it indicating that resistance determinants may spread among genetic lineages within the $V$. parahaemolyticus population. MGEs that carry resistance genes (Song et al., 2013) may be responsible for the high variation among the genotypes and resistance phenotypes of isolates. Therefore, we suggest future research to elucidate the precise mechanisms of resistance determinant transmission in $V$. parahaemolyticus populations.

\section{CONCLUSION}

Bacteria secrete toxin proteins or effectors into external media or directly into eukaryotic target cells to facilitate 
adaption to environmental stress conditions; this response is key during the process of infection (Park et al., 2004; Cascales, 2008; Tseng et al., 2009). Previous studies have revealed that clinical isolates of $V$. parahaemolyticus produce beta-hemolysis in Wagatsuma agar, in a process known as the Kanagawa phenomenon that is linked to TDHsecreted proteins. These proteins have been recognized as primary virulence factors and effectors (Naim et al., 2001; Ono et al., 2006; Igbinosa and Okoh, 2008). Studies from different regions of the world show that $t d h$ and/or trh genes are found in $90-99.8 \%$ of clinical strains, whereas only $0.2-10 \%$ of environmental $V$. parahaemolyticus isolates are potentially pathogenic, based on the presence of $t d h$ and/or trh (Letchumanan et al., 2015b; $\mathrm{Hu}$ and Chen, 2016; Taiwo et al., 2017; Rortana et al., 2018; Jiang et al., 2019).

Previous studies disclosed that $V$. parahaemolyticus is a very diverse species and is an opportunistic pathogen in aquatic environments that is highly successful in adapting to changing environmental conditions (Song et al., 2013; Letchumanan et al., 2015a,b). Increasing aquaculture production and industrialization has led to large amounts of antibiotics being used to prevent or treat disease outbreaks in shrimp farming; consequently, multidrug resistant (MDR) and heavy metals resistant pathogens have emerged and posed serious problems in many aquatic systems. It revealed that bacteria could acquire resistance via conjugation or transformation, allowing them to adapt to the harsh environment and to cause a wide variety of diseases (Matyar, 2012). Incidents of human food poisoning from aquaculture products pose a becoming a serious clinical issue.

In the present study, we evaluated the prevalence, antimicrobial susceptibility, heavy metal resistance and genotypes of $V$. parahaemolyticus from four species of shrimp obtained from fish markets in Jiangsu (in 2016-2018), China. The results showed that ICEs-positive isolates have been given more antibiotic resistance, and the MDR strains also showed more heavy metal resistance. Consistent with previous reports (Song et al., 2013; Hu and Chen, 2016; Kang et al., 2018), we found that AMP resistance dominated among the isolates and was present in all samples tested. Although TET, sulfonamides, and quinolones are used widely in aquaculture (Holmström et al., 2003), we did not find evidence of resistance to TET in the $V$. parahaemolyticus isolates. Nine isolates that tested positive for all resistance genes (strA/strB, $d f r A 1 / d f r 18$, sul2) exhibited intermediate susceptibility to $\mathrm{CN}$ and TET, indicating potential resistance to these two antibiotics. Our results for susceptibility of the $V$. parahaemolyticus isolates to CHL contrast with previous work (He et al., 2016), where we found all ICE-positive strains were resistant to $\mathrm{CHL}$, possibly as a result of the ban, since 2002, of the use of $\mathrm{CHL}$ and derivatives (including chloramphenicol succinate) in the breeding industry in China (China Department of Agriculture, Bulletin No. 193). We suggest that ICEpositive $V$. parahaemolyticus isolates may indicate tolerance to heavy metal agents.
Wide usage of teracyclines, sulfonamides, and (fluoro) quinolones in aquaculture has been reported (Holmström et al., 2003). In addition, animal fecal used as fertilizer of aquaculture ponds is a common practice in integrated aquaculture-agriculture system herein. Manure and urine from field-herding cattles and goats were continuously discharged directly into ponds, which could change the bacterial community composition and bring more antimicrobials and even heavy metals in the aquaculture environment. In the Vibrionaceae, ICEs have been demonstrated to bestow resistance to multiple antibiotics and some complex new traits through horizontal gene transfer, which could be beneficial under certain environmental conditions (Makino et al., 2003; Balado et al., 2013). However, the present study revealed that ICEs are not the major transmission mediators of resistance to antibiotics or heavy metals. Thus, we speculate that many of the antibiotic resistance genes are intrinsic, and their expressions are activated when the environmental conditions became hostile. Furthermore, few of them are commonly transferred via conjugation or transformation. These data will aid future research in controlling of aquaculture diseases, forecasting food safety incidence and improving our understanding of $V$. parahaemolyticus prevalence and behavior in the aquaculture.

\section{DATA AVAILABILITY}

The raw data supporting the conclusions of this manuscript will be made available by the authors, without undue reservation, to any qualified researcher.

\section{AUTHOR CONTRIBUTIONS}

$\mathrm{YH}, \mathrm{SW}, \mathrm{XZ}$, and JZ participated in the design and/or discussion of the study. FS, BH, and XL carried out the major experiments. YH and SW analyzed the data. YH wrote the manuscript. SW, XZ, and $\mathrm{JZ}$ revised the manuscript. All authors read and approved the final version of the manuscript.

\section{FUNDING}

This work was supported by grants from the National Science Foundation for Young Scientists of China (No. 31701566), the Natural Science Foundation of the Jiangsu Higher Education Institutions of China (No. 18KJB550011), the Subsidized Project of Brand Major Construction in Colleges and Universities of Jiangsu Province (PPZY2015B153 Food Science and Engineering), the Research Projects of Xuzhou University of Technology (No. XCX2019136), and the Henan Key Laboratory of Cold Chain Food Quality and Safety Control (No. CCFQ2018-YB-03). 


\section{REFERENCES}

Balado, M., Lemos, M. L., and Osorio, C. R. (2013). Integrating conjugative elements of the SXT/R391 family from fish-isolated Vibrios encode restrictionmodification systems that confer resistance to bacteriophages. FEMS Microbiol. Ecol. 83, 457-467. doi: 10.1111/1574-6941.12007

Bani, S., Mastromarino, P. N., Ceccarelli, D., Le Van, A., Salvia, A. M., Viet, Q. T. N., et al. (2007). Molecular characterization of ICEVchVie0 and its disappearance in Vibrio cholerae $\mathrm{O} 1$ strains isolated in 2003 in Vietnam. FEMS Microbiol. Lett. 266, 42-48.

Beker, M., Rose, S., Lykkebo, C. A., and Douthwaite, S. (2018). Integrative and conjugative elements (ICEs) in Pasteurellaceae species and their detection by multiplex PCR. Front. Microbiol. 9:1329. doi: 10.3389/fmicb.2018. 01329

Boyd, E. F., Cohen, A. L., Naughton, L. M., Ussery, D. W., Binnewies, T. T., Stine, O. C., et al. (2008). Molecular analysis of the emergence of pandemic Vibrio parahaemolyticus. BMC Microbiol. 8:110. doi: 10.1186/1471-2180$8-110$

Cascales, E. (2008). The type VI secretion toolkit. EMBO Rep. 9, 735-741. doi: 10.1038/embor.2008.131

Dalsgaard, A., Forslund, A., Tam, N. V., Vinh, D. X., and Cam, P. D. (1999). Cholera in Vietnam: changes in genotypes and emergence of class I integrons containing aminoglycoside resistance gene cassettes in Vibrio cholerae O1 strains isolated from 1979 to 1996. J. Clin. Microbiol. 37, 734-741.

Falbo, V., Carattoli, A., Tosini, F., Pezzella, C., Dionisi, A. M., and Luzzi, I. (1999). Antibiotic resistance conferred by a conjugative plasmid and a class I integron in Vibrio cholerae O1 El Tor strains isolated in Albania and Italy. Antimicrob. Agents Chemother. 43, 693-696.

Flores-Ríos, R., Moya-Beltrán, A., Pareja-Barrueto, C., Arenas-Salinas, M., Valenzuela, S., Orellana, O., et al. (2019). The type IV secretion system of ICEAfe1: formation of a conjugative pilus in Acidithiobacillus ferrooxidans. Front. Microbiol. 10:30. doi: 10.3389/fmicb.2019.00030

He, Y., Jin, L., Sun, F., Hu, Q., and Chen, L. (2016). Antibiotic and heavy-metal resistance of Vibrio parahaemolyticus isolated from fresh shrimps in Shanghai fish markets, China. Environ. Sci. Pollut. Res. Int. 23, 15033-15040. doi: 10.1007/ s11356-016-6614-4

He, Y., Tang, Y., Sun, F., and Chen, L. (2015a). Detection and characterization of integrative and conjugative elements (ICEs)-positive Vibrio cholerae isolates from aquacultured shrimp and the environment in Shanghai, China. Mar. Pollut. Bull. 101, 526-532. doi: 10.1016/j.marpolbul.2015.10.062

He, Y., Wang, H., and Chen, L. (2015b). Comparative secretomics reveals novel virulence-associated factors of Vibrio parahaemolyticus. Front. Microbiol. 6:707. doi: 10.3389/fmicb.2015.00707

Holmström, K., Gräslund, S., Wahlström, A., Poungshompoo, S., Bengtsson, B. E., and Kautsky, N. (2003). Antibiotic use in shrimp farming and implications for environmental impacts and human health. Int. J. Food Sci. Technol. 38, 255-266.

$\mathrm{Hu}$, Q., and Chen, L. (2016). Virulence and antibiotic and heavy metal resistance of Vibrio parahaemolyticus isolated from crustaceans and shellfish in shanghai, China. J. Food Prot. 79, 1371-1377. doi: 10.4315/0362-028X.JFP16-031

Igbinosa, E. O., and Okoh, A. I. (2008). Emerging Vibrio species: an unending threat to public health in developing countries. Res. Microbiol. 159, 495-506. doi: 10.1016/j.resmic.2008.07.001

Iwanaga, M., Toma, C., Miyazato, T., Insisiengmay, S., Nakasone, N., and Ehara, M. (2004). Antibiotic resistance conferred by a class I integron and SXT constin in Vibrio cholerae $\mathrm{O} 1$ strains isolated in Laos. Antimicrob. Agents Chemother. 48, 2364-2369.

Jiang, Y., Chu, Y., Xie, G., Li, F., Wang, L., Huang, J., et al. (2019). Antimicrobial resistance, virulence and genetic relationship of Vibrio parahaemolyticus in seafood from coasts of Bohai Sea and Yellow Sea, China. Int. J. Food Microbiol. 290, 116-124. doi: 10.1016/j.ijfoodmicro.2018.10.005

Johnson, C. M., and Grossman, A. D. (2015). Integrative and conjugative elements (ICEs): what they do and how they work. Annu. Rev. Genet. 49, 577-601. doi: 10.1146/annurev-genet-112414-055018

Kang, C. H., Shin, Y., Yu, H., Kim, S., and So, J. S. (2018). Antibiotic and heavymetal resistance of Vibrio parahaemolyticus isolated from oysters in Korea. Mar. Pollut. Bull. 135, 69-74. doi: 10.1016/j.marpolbul.2018.07.007
Kaysner, C., and DePaola, A. (2004). Bacteriological Analytical Manual Chapter 9: Vibrio. Silver Spring, MD: Food U.S. and Drug Administration.

Letchumanan, V., Pusparajah, P., Tan, L. T. H., Yin, W. F., Lee, L. H., and Chan, K. G. (2015a). Occurrence and antibiotic resistance of Vibrio parahaemolyticus from shellfish in Selangor, Malaysia. Front. Microbiol. 6:1417. doi: 10.3389/ fmicb.2015.01417

Letchumanan, V., Yin, W. F., Lee, L. H., and Chan, K. G. (2015b). Prevalence and antimicrobial susceptibility of Vibrio parahaemolyticus isolated from retail shrimps in Malaysia. Front. Microbiol. 6:33. doi: 10.3389/fmicb.2015.00033

Liu, M., Li, X., Xie, Y., Bi, D., Sun, J., Li, J., et al. (2019). ICEberg 2.0: an updated database of bacterial integrative and conjugative elements. Nucleic Acids Res. 47, D660-D665. doi: 10.1093/nar/gky1123

Lopatek, M., Wieczorek, K., and Osek, J. (2018). Antimicrobial resistance, virulence factors, and genetic profiles of Vibrio parahaemolyticus from seafood. Appl. Environ. Microbiol. 84:e00537-18. doi: 10.1128/AEM.00537-18

Makino, K., Oshima, K., Kurokawa, K., Yokoyama, K., Uda, T., Tagomori, K., et al. (2003). Genome sequence of Vibrio parahaemolyticus: a pathogenic mechanism distinct from that of $V$. cholerae. Lancet 361, 743-749.

Malik, A., and Aleem, A. (2011). Incidence of metal and antibiotic resistance in Pseudomonas spp. From the river water, agricultural soil irrigated with wastewater and groundwater. Environ. Monit. Assess. 178, 293-308. doi: 10.1007/s10661-010-1690-2

Martinez-Urtaza, J., Powell, A., Jansa, J., Rey, J. L., Montero, O. P., Campello, M. G., et al. (2016). Epidemiological investigation of a foodborne outbreak in Spain associated with U.S. West Coast genotypes of Vibrio parahaemolyticus. Springerplus 5:87. doi: 10.1186/s40064-016-1728-1

Matyar, F. (2012). Antibiotic and heavy metal resistance in bacteria isolated from the Eastern Mediterranean Sea coast. B. Environ. Contam. Tox. 89, 551-556. doi: 10.1007/s00128-012-0726-4

Naim, R., Yanagihara, I., Iida, T., and Honda, T. (2001). Vibrio parahaemolyticus thermostable direct hemolysin can induce an apoptotic cell death in Rat1 cells from inside and ouside of the cells. FEMS Microbiol. Lett. 195, 237-244.

Ono, T., Park, K. S., Ueta, M., Iida, T., and Honda, T. (2006). Identification of proteins secreted via Vibrio parahaemolyticus type III secretion system 1. Infect. Immun. 74, 1032-1042.

Pan, Z., Liu, J., Zhang, Y., Chen, S., Ma, J., Dong, W., et al. (2019). A novel integrative conjugative element mediates transfer of multi-drug resistance between Streptococcus suis strains of different serotypes. Vet. Microbiol. 229, 110-116. doi: 10.1016/j.vetmic.2018.11.028

Panicker, G., Call, D. R., Krug, M. J., and Bej, A. K. (2004). Detection of pathogenic Vibrio spp. In shellfish by using multiplex PCR and DNA microarrays. Appl. Environ. Microbiol. 70, 7436-7444.

Park, K. S., Ono, T., Rokuda, M., Jang, M. H., Okada, K., Iida, T., et al. (2004). Functional characterization of two type III secretion systems of Vibrio parahaemolyticus. Infect. Immun. 72, 6659-6665.

Rortana, C., Wajjwalku, W., Boonyawiwat, V., Hrianpreecha, C., Thongratsakul, S., and Amavisit, P. (2018). Antimicrobial resistance and pirAB-like profiles of Vibrio parahaemolyticus in Pacific white shrimp. Agric. Nat. Resour. 52, 377-381.

Rubio-Cosials, A., Schulz, E. C., Lambertsen, L., Smyshlyaev, G., Rojas-Cordova, C., Forslund, K., et al. (2018). Transposase-DNA complex structures reveal mechanisms for conjugative transposition of antibiotic resistance. Cell 173, 208-220.e20. doi: 10.1016/j.cell.2018.02.032

Seifert, H., Dolzani, L., Bressan, R., Van Der Reijden, T., Van Strijen, B., Stefanik, D., et al. (2005). Standardization and interlaboratory reproducibility assessment of pulsed-field gel electrophoresis-generated fingerprints of Acinetobacter baumannii. J. Clin. Microbiol. 43, 4328-4335.

Silva, I. P., Carneiro, C. S., Saraiva, M. A. F., Oliveira, T. A. S., Sousa, O. V., and Evangelista-Barreto, N. S. (2018). Antimicrobial resistance and potential virulence of Vibrio parahaemolyticus isolated from water and bivalve mollusks from Bahia, Brazil. Mar. Pollut. Bull. 131, 757-762. doi: 10.1016/j.marpolbul. 2018.05.007

Song, Y., Yu, P., Li, B., Pan, Y., Zhang, X., Cong, J., et al. (2013). The mosaic accessory gene structures of the SXT/R391-like integrative and conjugative elements derived from Vibrio spp. Isolated from aquatic products and environment in the Yangtze River Estuary, China. BMC Microbiol. 13:214. doi: 10.1186/1471-2180-13-214 
Taiwo, M., Baker-Austin, C., Powell, A., Hodgson, E., Natås, O. B., and Walker, D. I. (2017). Comparison of toxR and th based PCR assays for Vibrio parahaemolyticus. Food Control 77, 116-120.

Thapa Shrestha, U., Adhikari, N., Maharjan, R., Banjara, M. R., Rijal, K. R., Basnyat, S. R., et al. (2015). Multidrug resistant Vibrio cholerae O1 from clinical and environmental samples in Kathmandu city. BMC Infect. Dis. 15:104. doi: 10.1186/s12879-015-0844-9

Tseng, T. T., Tyler, B. M., and Setubal, J. C. (2009). Protein secretion systems in bacterial-host associations, and their description in the Gene Ontology. BMC Microbiol. 9(Suppl. 1):S2. doi: 10.1186/1471-2180-9-S1-S2

Weisburg, W. G., Barns, S. M., Pelletier, D. A., and Lane, D. J. (1991). 16S ribosomal DNA amplification for phylogenetic study. J. Bacteriol. 173, 697-703.

WHO (2014). Antimicrobial Resistance: Global Report on Surveillance 2014. Geneva: WHO.

Woolhouse, M., and Farrar, J. (2014). Policy: an intergovernmental panel on antimicrobial resistance. Nature 509, 555-557.

Xu, J., Jia, H., Cui, G., Tong, H., Wei, J., Shao, D., et al. (2018). ICEAplChn1, a novel SXT/R391 integrative conjugative element (ICE), carrying multiple antibiotic resistance genes in Actinobacillus pleuropneumoniae. Vet. Microbiol. 220, 18-23. doi: 10.1016/j.vetmic.2018.05.002

Zhao, S., Ma, L., Wang, Y., Fu, G., Zhou, J., Li, X., et al. (2018). Antimicrobial resistance and pulsed-field gel electrophoresis typing of Vibrio parahaemolyticus isolated from shrimp mariculture environment along the east coast of China. Mar. Pollut. Bull. 136, 164-170. doi: 10.1016/j.marpolbul.2018. 09.017

Conflict of Interest Statement: The authors declare that the research was conducted in the absence of any commercial or financial relationships that could be construed as a potential conflict of interest.

Copyright (C) 2019 He, Wang, Zhang, Zhang, Sun, He and Liu. This is an open-access article distributed under the terms of the Creative Commons Attribution License (CC BY). The use, distribution or reproduction in other forums is permitted, provided the original author(s) and the copyright owner(s) are credited and that the original publication in this journal is cited, in accordance with accepted academic practice. No use, distribution or reproduction is permitted which does not comply with these terms. 